\title{
SciaticNeuralgia an Agonising Encumbrance and its Modern Approach
}

\author{
Avinash Shankar ${ }^{1 *}$, Amresh Shankar ${ }^{2}$ and Anuradha Shankar ${ }^{3}$ \\ ${ }^{1}$ Chairman National Institute of Health \& Research Warisaliganj, India \\ ${ }^{2}$ Honorary Director State Health Services, Government of Bihar AarogyamPunarjeevan, India \\ ${ }^{3}$ Director Centre for Indigenous Medicine \& Research Warisaliganj, India \\ *Corresponding author: Avinash Shankar, Chairman, National Institute of Health \& Research Warisaliganj (Nawada) Bihar 805130, India
}

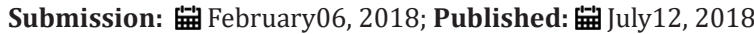

\begin{abstract}
Sciatica not a medical diagnosis but is a symptom of an underlying vertebral condition i.e.,-lumbar herniation. dislocated disc, Spondylolisthesis and spinal stenosiswhere usually practiced medicine.Physicaltherapy, surgery and even alternative therapyfails to ensure cure but present regimea composite ofintravenous Calcium supplementation, cholecalciferoland bio neurogen composite achieved grade I clinical response in $93 \%$ cases without anywithdrawal. Drug adversity, hepatorenal alteration and recurrence in 5yrs of post therapy follow up with excellent quality of life.
\end{abstract}

Keywords: Sciatic neuralgia; Radiculitis; Spondylolisthesis; Spinal stenosis; Lumbar disc herniation; Bio neuragen

\section{Introduction}

Sciatica a clinical condition presenting with leg pain, tingling and numbness, weakness in the lower back radiating down wards up to legs both front and outside which is usually due to either lumbar herniated disc, degenerative disc disease, Spondylolisthesis or spondylolithiasis or spinal stenosis. This affect $2 \%-40 \%$ of population presenting with encumbrance at same point of life in the age group of 40-50 years and men outnumber women [1].

The literature reveals use of analgesics, steroids to relieve pain, may relieve pain but fails to alleviate presentation, though use of Gabapentine for acute is quite in vogue but non ensure satisfactory clinical relief or improved quality of life. In addition, alternative therapy like Spinal manipulation and surgery are also in vogue with intent to alleviate agonising state [2]. Thus, in this agonising disease having no secured curative therapeutic modality a clinical evaluation program is conducted at RA.Hospital \& Research Centre, Warisaliganj (Nawada) Bihar.

\section{Aims and Objectives}

Asses the clinical efficacy of a combo therapeutic modality in cases non responsive to Sciatica of varied origin and etio pathogenesis.

\section{Materials\& Method}

Patients of sciatica of various etiopathogenesis attending medical OPD of RA. Hospital \& Research Centre, Warrisaliganj (Nawada) Bihar been selected as per following index-Patients with-
A. Constant pain in only one side of the leg or buttock [3]

B. Pain originates in low back or buttock and continues along the path of sciatic nerve down the back of the thigh, lower leg and foot.

C. Pain becomes worse on sitting or standing, exacerbate on sneezing or coughing

D. Pins and needle sensation, numbness, weakness or pricking sensation

E. Weakness Or numbness on moving the leg or foot

F. Severe or shooting pain in the leg

G. Pain and other symptoms in toes.

All the selected patients were thoroughly interrogated, examined and assessed for straight leg raising test (Positive Lasegue's Sign) i.e.- Pain in the distribution of Sciatic nerve, blood sugar, hepato renal status to ascertain post therapy drug related adversity.

Based on clinical presentation and its severity patients were classified in Table 1. Patients having associated hypertension, myxoedema (hypothyroidism) and diabetes mellitus are duly controlled with dietary restriction and drug therapy. In diabetes mellitus and hypertension carbohydrate and high fat dietare duly restricted,in addition all the cases with hyper lipidemic state baked 
seed of Linseed (Linumusitatissimum)in dose of $5 \mathrm{gm}$ morning and evening to be chewed daily. Prior to advocation of trial drug patients were re assured for bio regulated blood sugar, serum cholesterol and blood pressure. In addition, persons with body weight >IBW been suggested for dietary control to ensure IBW to alleviate pressure over the vertebral column due to overweight [4].

Table 1: Clinical presentation and its severity of the patients.

\begin{tabular}{|c|c|}
\hline \multicolumn{2}{|c|}{ Straight leg raising test (Lasegue's sign ): Presence of Pain in the Distribution of Sciatic Nerve on Passive Flexion of Straight Leg between 30- } \\
$\mathbf{7 0}$ Degree Elevation
\end{tabular}

\section{Regime prescribed}

Injection Calcium Gluconate 1 ampoule intravenous very slow with 24 numbered scalp vein set (Measure blood pressure, in hypertensive Calcium should be avoided)

Inj Methyl cobalamin 1500mcg+Nicotinamide+Pyridoxin 1 ampoule every $4^{\text {th }}$ day very slow Cap Bio neuragen 1 cap daily Or Syrup $10 \mathrm{ml} 12 \mathrm{hrly}$ for adult [Bio neuragen constitutes natural resource i.e.- equal part of powder of Acorus calamus (rhizome), Herpestismonnieri (leaf), Nardostachysjatamansi (flower), Convolvulus pluricaulis (Flower)either in capsule form or syrup constituting $500 \mathrm{mg}$ each capsule or $500 \mathrm{mg}$ each $10 \mathrm{ml}]$.

Proton pump inhibitor and analgesic anti arthritic (Aceclofenac sustained release with rabiprazol(Cap Dolostat $+\mathrm{R}$ OrRaceclo1cap daily). Active and passive exercise Cap Cholecalciferol D3 60K every week, Each patient been given a follow up card with facility to enter in Table 2. On every 3 months patient's blood analysis for blood sugar, hepatic, haematological and renal function were assessed to ascertain any drug adversity and safety profile of the advocated regime. Based on therapeutic response, clinical achievement been graded in Table 3.
Table 2: Follow up card.

\begin{tabular}{|c|l|l|}
\hline Particulars & Date of Achievement & Any Unusual \\
\hline Leg pain & & \\
\hline Back pain & & \\
\hline Agony on sneezing/coughing & & \\
\hline SLR & & \\
\hline
\end{tabular}

Table 3: Grading of clinical achievement based on therapeutic response.

\begin{tabular}{|c|c|}
\hline $\begin{array}{c}\text { Grade I (Ex- } \\
\text { cellent) }\end{array}$ & $\begin{array}{c}\text { Improvement in pain and agony within a week of thera- } \\
\text { py with complete normalcy in gait in 3 months therapy } \\
\text { without any adversity or adjuvant. }\end{array}$ \\
\hline $\begin{array}{c}\text { Grade II } \\
\text { (Good) }\end{array}$ & $\begin{array}{c}\text { Relief in agonizing pain and improvement in other pre- } \\
\text { senting features }\end{array}$ \\
\hline $\begin{array}{c}\text { Grade } \\
\text { III(Poor) }\end{array}$ & Symptomatic relief with recurrence \\
\hline
\end{tabular}

\section{Observations}

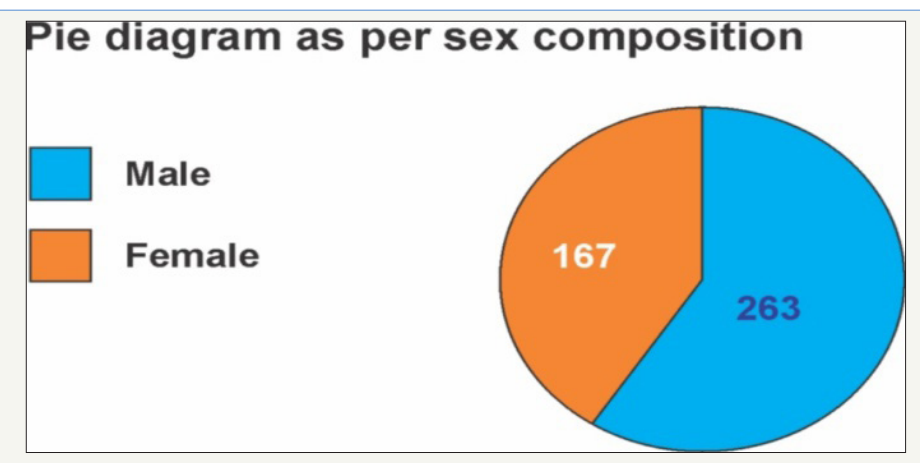

Figure 1: Pie diagram as per sex composition.

Selected patients were of age group above 20 years and among them majority (20.5\%) were of age group 30-35 years while $18 \%$ patients were of age $>50$ years Table 4 . Out of all $65.7 \%$ were male and $34.25 \%$ were female Figure 1.

Out of all $47 \%$ patients were suffering since $>5$ years and $4.5 \%$ were from $>10$ years while majority $(21.25 \%)$ patients since last 3-4 years Table 5. As per occupation majority (127) were house hold workerwhile 85 were labourer, 116 were motor cyclist and 29 were cyclist, and 55 were leading sedentary life style Table 6. Among them $210(52.5 \%)$ were of severe degree of clinical presentation while $180(35 \%)$ moderate and $10(2.5 \%)$ mild Figure 2. As per clinical diagnosis majority (71.5\%) were of radiculitis while $12.5 \%$ were of spinal disc herniation Table 6. $2.75 \%$ patients were with low body weight while $40 \%$ were obese and overweight, $62.25 \%$ were normotensive while $0.5 \%$ was hypertensive Table $7.64 .2 \%$ male and $74.5 \%$ female were with fasting blood sugar $<100 \mathrm{mg} \%$ while 
$2.6 \%$ male and $4.3 \%$ female with blood sugar $>150 \mathrm{mg} .35 .7 \%$ male and $25.5 \%$ female were with haemoglobin concentration $<10$ gm $\%, 2.3 \%$ male and 3.6\% female were with SGOT and SGPT $>35 \mathrm{IU}, 22.4 \%$ male and 5.1\% female were with blood urea $>30 \mathrm{mg} \%$ and Serum creatinine $>1.5 \mathrm{mg} \%$. $93 \%$ patients had grade I clinical response while $6.5 \%$ shows grade II with relapse in $0.5 \%$ cases [5]. None shows any drug adversity or needed any adjuvant or had acute surge of presenting agony Table 8.

Table 4: Age and sex wise distribution of patients of sciatic neuralgia.

\begin{tabular}{|c|c|c|c|}
\hline \multirow{2}{*}{$\begin{array}{c}\text { Age Group } \\
\text { (in years ) }\end{array}$} & \multicolumn{3}{|c|}{ Number of Patients } \\
\cline { 2 - 4 } & Male & Female & Total \\
\hline $20-25$ & 35 & 20 & 55 \\
\hline $25-30$ & 38 & 12 & 50 \\
\hline $30-35$ & 58 & 24 & 82 \\
\hline $35-40$ & 31 & 19 & 50 \\
\hline $40-45$ & 27 & 16 & 43 \\
\hline $45-50$ & 29 & 19 & 48 \\
\hline$>50$ & 45 & 27 & 72 \\
\hline Total & 263 & 137 & 400 \\
\hline
\end{tabular}

Table 5: distribution of patients as per duration of illness.

\begin{tabular}{|c|c|c|c|}
\hline \multirow{2}{*}{ Duration in Years } & \multicolumn{3}{|c|}{ Number of patients } \\
\cline { 2 - 4 } & Male & Female & Total \\
\hline$<1 \mathrm{yr}$ & 7 & 10 & 17 \\
\hline $01-02$ & 17 & 6 & 23 \\
\hline $02-03$ & 29 & 15 & 44 \\
\hline $03-04$ & 56 & 29 & 85 \\
\hline $04-05$ & 28 & 15 & 43 \\
\hline $05-06$ & 20 & 8 & 28 \\
\hline $06-07$ & 19 & 11 & 30 \\
\hline $07-08$ & 31 & 17 & 48 \\
\hline $08-09$ & 28 & 12 & 40 \\
\hline $09-10$ & 16 & 8 & 24 \\
\hline$>10$ & 12 & 6 & 18 \\
\hline
\end{tabular}

Table 6: Distribution of patients as per occupation.

\begin{tabular}{|c|c|c|c|}
\hline \multirow{2}{*}{ Occupation } & \multicolumn{3}{|c|}{ Number of Patients } \\
\cline { 2 - 4 } & Male & Female & Total \\
\hline Labourer & 76 & 9 & 85 \\
\hline Motor cyclist & 107 & 9 & 116 \\
\hline Cyclist & 29 & 0 & 29 \\
\hline
\end{tabular}

\begin{tabular}{|c|c|c|c|}
\hline House hold worker & 23 & 104 & 127 \\
\hline Sedentary life style & 40 & 15 & 55 \\
\hline
\end{tabular}

Table 7: Distribution of patients as per their body weight and blood pressure.

\begin{tabular}{|c|c|c|c|c|c|}
\hline \multirow{2}{*}{$\begin{array}{c}\text { Body Weight } \\
\text { Blood Pressure }\end{array}$} & \multicolumn{5}{|c|}{$\begin{array}{c}\text { Number of Patients } \\
\text { Average Blood Pressure(mmHg) }\end{array}$} \\
\cline { 2 - 7 } & $<\mathbf{1 0 0}$ & $\mathbf{1 0 0 - 1 1 0}$ & $\mathbf{1 1 0 - 1 2 0}$ & $\mathbf{1 2 0 - 1 3 0}$ & $>\mathbf{1 3 0}$ \\
\hline IBW & 99 & 24 & & - & - \\
\hline IBW+ 1SD & 120 & 4 & - & - & 1 \\
\hline IBW+ 2SD & 17 & 3 & 2 & 1 & - \\
\hline IBW+3SD & 10 & 2 & - & - & - \\
\hline IBW+4SD & 4 & 2 & - & - & - \\
\hline IBW-1SD & 4 & 7 & - & - & - \\
\hline \multicolumn{7}{|c|}{ (Key word: IBW: Ideal body weight as per age , 1SD = 5kg } \\
\hline
\end{tabular}

Table 8: Distribution of patient as per haematological, hepatic and blood sugar status.

\begin{tabular}{|c|c|c|c|}
\hline \multirow{2}{*}{ Particulars } & \multicolumn{3}{|c|}{ Number of Patients } \\
\hline & Male & Female & Total \\
\hline \multicolumn{4}{|c|}{ Blood sugar } \\
\hline \multicolumn{4}{|c|}{ Fasting: } \\
\hline$>100 \mathrm{mg} \%$ & 169 & 102 & 271 \\
\hline $100-150 \mathrm{mg} \%$ & 87 & 29 & 116 \\
\hline $150-200 \mathrm{mg} \%$ & 7 & 6 & 13 \\
\hline \multicolumn{4}{|c|}{ Haematological } \\
\hline \multicolumn{4}{|c|}{ Haemoglobin (gm \%) } \\
\hline$<10 \mathrm{gm}$ & 94 & 35 & 129 \\
\hline$>10 \mathrm{gm}$ & 169 & 102 & 271 \\
\hline \multicolumn{4}{|c|}{ Hepatic profile } \\
\hline \multicolumn{4}{|c|}{ SGOT (in IU): } \\
\hline$<35$ & 257 & 132 & 389 \\
\hline$>35$ & 6 & 5 & 11 \\
\hline \multicolumn{4}{|c|}{ SGPT (in IU) } \\
\hline$<35$ & 257 & 132 & 389 \\
\hline$>36$ & 6 & 5 & 11 \\
\hline \multicolumn{4}{|c|}{ Renal profile } \\
\hline \multicolumn{4}{|c|}{ Blood Urea (in mg \%) } \\
\hline$<30$ & 204 & 130 & 334 \\
\hline$>30$ & 59 & 7 & 66 \\
\hline \multicolumn{4}{|c|}{ Serum creatinine (in mg \%) } \\
\hline$<1.5$ & 204 & 130 & 334 \\
\hline$>1.5$ & 59 & 7 & 66 \\
\hline
\end{tabular}




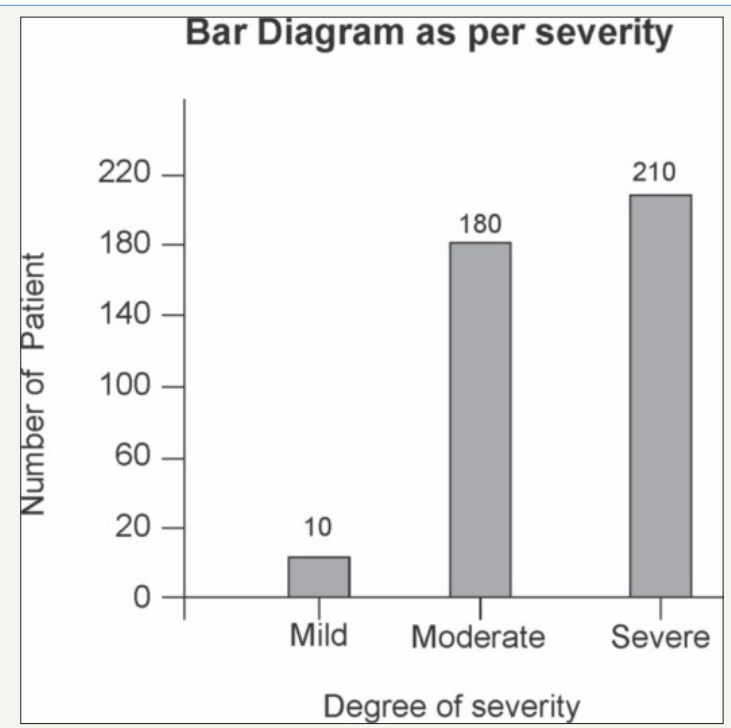

Figure 2: Bar diagram as per severity.

\section{Result}

Patients of sciatic neuralgia Or Sciatica of varying stage and etiopathogenetics of age group 20-50 years non-responsive to various conventional and recommended therapeutics, had grade I clinical response in $93 \%$ patients with present therapeutic modality (Figure 3).

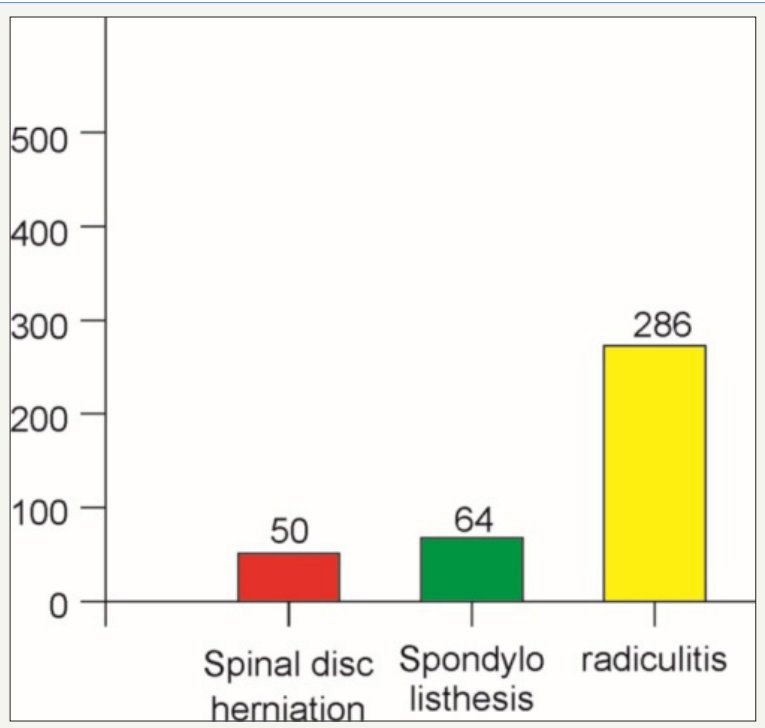

Figure 3: Bar diagram showing radiological diagnosis.

\section{Discussion}

Table 9: Outcome of therapy.

\begin{tabular}{|c|c|}
\hline Particulars & Number of Patients \\
\hline Any drug adversity & None \\
\hline Any adjuvant required & None \\
\hline \multicolumn{2}{|c|}{ Status on treatment withdrawal } \\
\hline Relapse & 2 \\
\hline Rebound & None \\
\hline Unaltered & 398 \\
\hline \multicolumn{2}{|c|}{ Grades of clinical response } \\
\hline
\end{tabular}

\begin{tabular}{|c|c|}
\hline Grade I & 372 \\
\hline Grade II & 26 \\
\hline Grade III & 2 \\
\hline
\end{tabular}

Sciatica, an agonising presentation in area supplied by sciatic nerve i.e. back to posterior part of lower extremity up to heel, though conventional management i.e. drugs, physiotherapy and surgical intervention fails to achieve cure the present study comprising use of therapeutic modality achieve grade I clinical response in $93 \%$ patients while $0.5 \%$ cases had grade III response as etio pathogenesis of sciatic pain is usually due to decline neuro conduction, glial damage and neuronal oedema ,in addition increasing incidence is solely due to changed life style [6], presence of dietary non nutrients which causes toxic glial necrosis 
or degeneration Table 9. Intravenous Calcium supplementation provide ionic calcium to boost neuro transmission and conduction, Chole calciferol helps in fatty acid bioregulation and ionic calcium concentration, biogenic neurogenic constituents i.e.-active ingredients of Acorus calamus, Herpestis monnieri, Nardostachys jatamansi, Convolvulus pluricaulis and Cassia angustifolia helps in neuroglial regeneration, disc repair,limit inflammation. Analgesic antarthritic aceclofenac sodium 200mg (SR) helps in acute pain relief while Proton pump inhibitor safe guard gastric mucosa. Bio regulative effect of biogenic neuragen checks recurrence or withdrawal due to its neuro generative effect [7].

\section{References}

1. Ropper AH, Zafonte RD (2015) Sciatica. N Engl J Med 372(13): 12401248.
2. Valat JP, Genevay S, Marty M, Rozenberg S, Koes B (2010) Sciatica. Best Pract Res Clin Rheumatol 24(2): 241-252.

3. Koes BW, Van Tulder MW, Peul WC (2007) Diagnosis \& treatment of sciatica. BMJ 334(7607): 1313-1317.

4. Pinto RZ, Maher CG, Ferriera ML, Ferriera PH, Hancock M, et al. (2012) Drugs for relief of pain in patients with Sciatica, systemic review and meta analysis. BMJ 344: e497.

5. Rasmussen BE, Held U, Grooten WJ, Roelofs PD, Koes BW, et al. (2016) Non-steroidal anti inflammatory drugs for sciatica. Cochrane Database Syst Rev 10: CD012382.

6. Waseem Z, Boulias C, Gordon A, Ismail FSG, Furlan AD, et al. (2011) Botulinum toxin injection for low back pain and sciatica. Cochrane Database Syst Rev 1: CD008257.

7. Chou R, Hashimoto R, Friedly J, Fu R, Bougatsos C, et al. (2015) Epidural corticosteroid injection for radiculopathy and spinal stenosis. A systemic Review and Meta analysis. Ann Intern Med 163(5): 373-381.
Creative Commons Attribution 4.0 International License

For possible submissions Click Here

\section{Submit Article}

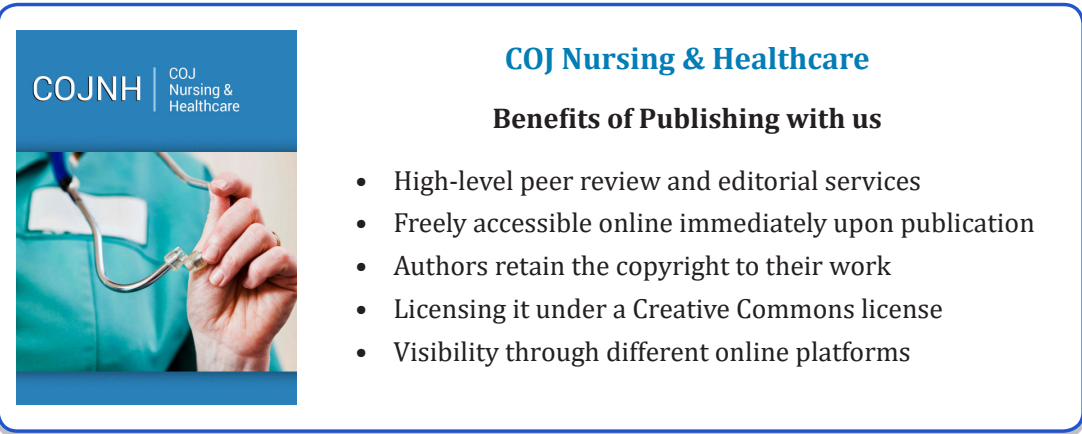

